\title{
Experimental analysis of an effect of the nutrient type and its concentration on the rheological properties of the baker's yeast suspensions
}

\author{
Marta Major-Godlewska*, Marcelina Bitenc, Joanna Karcz \\ West Pomeranian University of Technology, Szczecin, Department of Chemical Engineering, al. Piastów 42, PL-71 065 \\ Szczecin, Poland \\ "Corresponding author: mmajor@zut.edu.pl
}

\begin{abstract}
The aim of the study presented was to experimentally analyze an effect of the nutrient type and its concentration on the variability of rheological properties of the baker's yeast suspensions for different time periods. Aqueous suspensions of the baker's yeast of various concentration (solution I, without nutrient) and yeasts suspended in aqueous solution of sucrose or honey as nutrients with different concentration (solution II or solution III) were tested. Experiments were carried out using rotational rheoviscometer of type RT10 by a company HAAKE. The measurements were conducted for different time periods (from $1 \mathrm{~h}$ up to $144 \mathrm{~h}$ ) at given fluid temperature. On the basis of the obtained data, rheological characteristics of the aqueous solution of baker's yeast suspensions without and with nutrients of different sucrose or honey concentration were identified and mathematically described.
\end{abstract}

Keywords: rheological properties, baker`s yeast suspension.

\section{INTRODUCTION}

Recently, fast development in technology has required knowledge on physical properties of rheologically complex fluids such as, for example, suspensions (Sato et al. $\left.{ }^{1}\right)$, emulsions, pastes (Pereira de Oliviera et al. ${ }^{2}$ ), or biofluids (Klein et al. ${ }^{3}$, Yu et al. ${ }^{4}$ ).

Yeast Saccharomyces cerevisiae are commonly used in food industry, brewing of beer and distilling. When designing the bioreactor and technology of the bioproduct, physical and rheological characteristics of the fluids used in a given bioprocess are important.

Technical aspects of the rheological properties of microbial cultures were discussed in detail by Charles ${ }^{5}$. Reuss et al. ${ }^{6}$ undertook successful attempts to explain the discrepancies between literature data concerning rheological characteristics of yeast suspension. As the main problem in rheological measurements, authors specified measuring uncertainty during determination of the volumetric fraction of the biophase in a suspension. It can affect the differences between results of the computations based on the empirical correlations presented in literature.

El-Temtamy et al. ${ }^{7}$ carried out the measurements of the viscosity for the suspension of the baker's yeast in water and aqueous solutions of methanol, as well as of electrolytes. Authors described obtained results using power law model for the non-Newtonian fluids and assuming flow index $n<1$ (characteristic for pseudoplastic liquids) constant for whole range of the performed experiments.

Speers et al. ${ }^{8}$ studying the flocculation effect in the yeast suspensions proposed rheological model for such system related with the Bingham model and taking into consideration viscoelastic properties of the cells.

Extensive investigations of the rheological properties of aqueous suspensions of baker's yeast were carried out by Mancini \& Moresi ${ }^{9}$. The measurements were conducted by means of the three types of the rheometrical instruments. Authors suggested that discrepancies between obtained results were caused by different sensitivity of the used rheometres.

Klein et al. ${ }^{3}$ undertook the study related with the rheological properties of the yeast cells. Authors stated that two regions can be distinguished in rheological characteristics for such suspension systems. Namely, these systems behave as Newtonian fluids when yeast concentration in a liquid is less than $59 \mathrm{~kg} / \mathrm{m}^{3}$, whereas above this concentration they behave as the shear thinning fluids. Additionally, Klein et al. $^{3}$ stated that such suspensions are the fluids with yield stress $\tau_{o}$, which increases with the increase of the concentration of the microorganism floccules, however it is difficult to determine within the region of the low shear rates.

$\mathrm{Yu}$ et $\mathrm{al}^{4}{ }^{4}$ presented the results of the rheological properties measurements for flocculating aqueous suspensions of the yeast with a given concentration $X$ of biomass. Authors stated that suspension with the concentration $X$ lower than $2.3 \mathrm{~kg} / \mathrm{m}^{3}$ behaves as Newtonian fluid for reason of dominating effect of the physical properties of the continuous phase. On the flow curves, Yu et al. ${ }^{4}$ did not observe yield stress $\tau_{o}$ for the suspension with the biomass concentration lower than $X=40 \mathrm{~kg} / \mathrm{m}^{3}$ and they assumed that this suspension behaves as pseudoplastic liquid. However, rheological character of the suspensions with higher concentration of biomass was different, namely such suspensions behaved as shear thinning fluids with yield stress $\tau_{0}$. The study carried out by $\mathrm{Yu}$ et al. ${ }^{4}$ confirm the suppositions that dimensions of the floccules and impact between cells resulting in formation aggregates affect mainly non-Newtonian character of the biological suspensions.

Systems which contain microorganisms (biofluids) are characterized by diversity and variability due to rheological properties. Therefore, application of the rheological models, prepared on the basis of the experimental data obtained for inanimate mediums, to the description of rheological characteristics of biofluids should be considered as approximation only. Up to now in literature data, experimental results have been successfully discussed in order to determine the effects of the microorganisms fraction on the rheological properties and shape of the flow curves for the biofluids. However, the attempts concerning explanation of the possible variability of the rheological characteristics for biofluids in a process time have not been discussed sufficiently in literature. The 
aim of the study presented in this paper was to experimentally estimate an effect of the nutrient type and its concentration on the variability of rheological properties of the aqueous suspensions with different concentration of the baker's yeast for different time periods.

\section{MATERIAL AND METHODS}

Rheological measurements were carried out using rheoviscometer type RT10 by company Haake with the system of two co-axial cylinders. Measurements were conducted for the shear rate $\gamma \leq 4001 / \mathrm{s}$ and temperature of the fluid equal to $23^{\circ} \mathrm{C}$. The initial stage of each bioprocess involves important operations on the level of the up-stream engineering. In general, such operations occur in lower temperature than fermentation process. Because rheological properties of biomaterials strongly depend on process temperature, therefore, knowledge of such data is needed for that stage of the bioprocess.

Experiments were carried out for three types of the baker's yeast suspensions differing in the yeast concentration $X$, concentration of the nutrient $c$ and sampling time $t$ after which rheological properties were tested. Yeasts were dispersed in demineralised water and aqueous sucrose and natural polyfloral honey solutions (in further part of the text "honey solution"). In this case, sucrose and honey were applied as the nutrients. Using honey as nutrient can be alternative source of sucrose in processes of food industry, occurring with the use of yeasts.

Fresh pressed baker's yeast Saccharomyces cerevisiae produced by Lesaffre Polska S.A. were used in the experimental study. Yeast suspensions were prepared in the flask and they were maintained in the temperature about $22^{\circ} \mathrm{C}$. Before beginning the rheological measurements, each of prepared yeast suspensions was shaken by 5 minutes to obtain homogeneous mixture. Determined experimentally content of the dry biomass was equal to $30 \%$ mass of raw material used. This fact was taken into account during estimation of the yeast concentration in analysed samples.

First solution (solution I) used in the study had concentration of yeast in demineralised water equal to $X$ $=4,8,12,16,25,50,100,150,200$ or $250 \mathrm{~kg} / \mathrm{m}^{3}$ and it had not contained any nutrient. For this solution, experiments were performed in the following time periods: after $t=1 \mathrm{~h}, 24 \mathrm{~h}, 48 \mathrm{~h}, 72 \mathrm{~h}$ and $96 \mathrm{~h}$, respectively, from the moment of the yeast suspension preparation. In second solution (solution II), concentration of yeast was equal to $X=100 \mathrm{~kg} / \mathrm{m}^{3}$ in aqueous solution of sucrose with concentration $c=0.02,0.05,0.1$ or 0.2 $\mathrm{kg} / \mathrm{kg}_{\text {solution. }}$. In this case experiments were performed in the following time periods: after $t=1 \mathrm{~h}, 24 \mathrm{~h}, 48 \mathrm{~h}, 72$ $\mathrm{h}, 144 \mathrm{~h}$ respectively, from the moment of the solution II preparation. Concentration of yeast for third solution (solution III) was equal to $X=100 \mathrm{~kg} / \mathrm{m}^{3}$ in aqueous solution of honey with concentration $c=0.02$ or $0.1 \mathrm{~kg} /$ $\mathrm{kg}$. In this case, the same periods of time $t$ were taken into account as for the solution I, i.e. $t \in<1 \mathrm{~h}$; $96 \mathrm{~h}\rangle$. In total, 120 rheological characteristics in the form of both flow curves $\tau=\mathrm{f}(\gamma)$ and viscosity curves $\eta_{a}=\mathrm{f}(\gamma)$ were obtained for all three yeast suspensions.

\section{RESULTS AND DISCUSSION}

Yeasts suspended in demineralised water (solution I)-

On the basis of the results obtained for the five series of the measurements within the range of the yeast concentration in the demineralised water $X=25,50$, $100,150,200$ and $250 \mathrm{~kg} / \mathrm{m}^{3}$ and time $t \in<1 \mathrm{~h} \div 96 \mathrm{~h}$ $>$, the flow curves $\tau=\mathrm{f}(\gamma)$ were found. Analysis of the curves shape shows that dependence of the shear stress $\tau$ on the shear rate $\gamma$ can be described in this case using Ostwald - de Waele equation (Ferguson \& Kembłowski ${ }^{\mathbf{1 0}}$ )

$\tau=k \cdot(\gamma)^{n}$

where $n$ denotes flow index and $k$ is consistency index. In Figure 1, the dependence $n=\mathrm{f}(t)$ is shown for the yeast concentration $X=25,50,100,150,200$ and 250 $\mathrm{kg} / \mathrm{m}^{3}$ in the aqueous suspension. It can be observed that values of the flow index $n$ do not differ significantly within the both ranges of time periods $1 \mathrm{~h}<t<96 \mathrm{~h}$ and yeast concentration $X \in\left(25 \mathrm{~kg} / \mathrm{m}^{3} \div 150 \mathrm{~kg} / \mathrm{m}^{3}\right)$. Therefore, it was assumed constant value of the $n=$ $0.885 \pm 0.026$ within the both ranges of the variables $t$ and $X$. Absence of the significant changes in value of the flow index $n$ as a time function, as well as less more than one value of the $n$ suggest that samples of the yeast suspensions within these ranges of the $X$ and $t$ variables can be classified to the non-Newtonian fluid of properties of the shear thinning liquid (pseudoplastic liquid). However, significantly higher values of the flow index $n$ were obtained for the suspension with yeast concentration equal to $X=200 \mathrm{~kg} / \mathrm{m}^{3}$ tested within the time periods $t$ from $1 \mathrm{~h}$ to the $96 \mathrm{~h}$. In this case, value of the $n$ in Eq. (1) changed slightly only within the following range $1.024<n<1.061$. Therefore, this yeast suspension can be identified as Newtonian fluid. The change of the fluid character from shear thinning to the shear thickening properties confirm the experiments conducted within the same range of the time $t$ for the suspension of the yeast with the concentration $X=250$ $\mathrm{kg} / \mathrm{m}^{3}$. In this case, value of the flow index was equal to $n=1.242$ within first time period, i.e. after $t=1 \mathrm{~h}$. This value of the $n$ was maintained on the same level also within the next time periods. Taking into account values

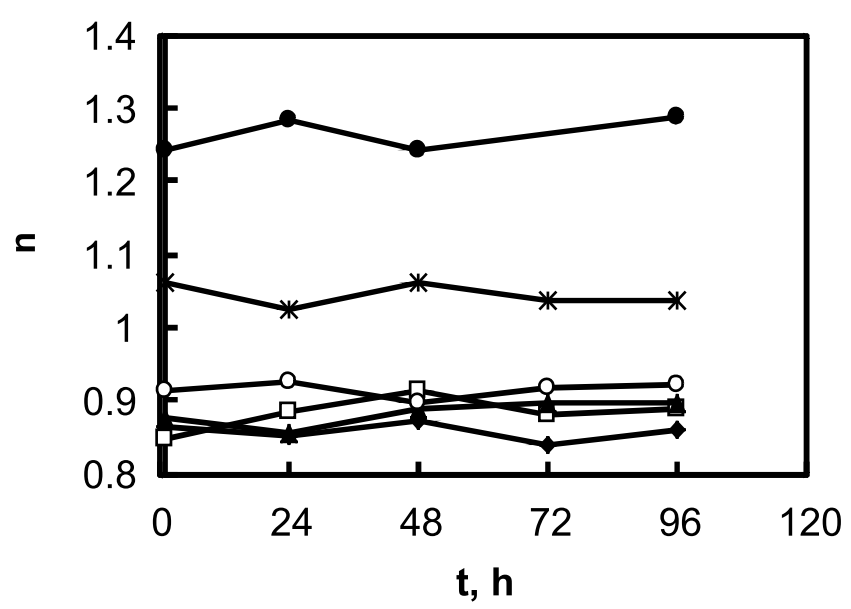

Figure 1. Dependence $n=\mathrm{f}(t)$ for the concentration $X=25,50,100,150,200$ or $250 \mathrm{~kg} / \mathrm{m}^{3}$ yeast in aqueous suspension; $X: 25 \mathrm{~kg} / \mathrm{m}^{3}(\diamond), 50$ $\mathrm{kg} / \mathrm{m}^{3}(\square), 100 \mathrm{~kg} / \mathrm{m}^{3}(\Delta), 150 \mathrm{~kg} / \mathrm{m}^{3}$ (○), 200 $\mathrm{kg} / \mathrm{m}^{3}\left(^{*}\right), 250 \mathrm{~kg} / \mathrm{m}^{3}(\bullet)$ 
of the flow index $n$ obtained within the whole range of the yeast concentration $X$, it can be concluded that aqueous solution of the yeast tested in the performed experiments cannot be ascribed unequivocally to one category of the non-Newtonian fluid.

The value of the flow index from Eq. (1) equal to $n=0.885 \pm 0,026$ describes with good accuracy also the rheological data obtained after the time $t=1 \mathrm{~h}$ for the yeast suspensions of smaller concentration $X=4,8,12$ or $16 \mathrm{~kg} / \mathrm{m}^{3}$ (Fig. 2).

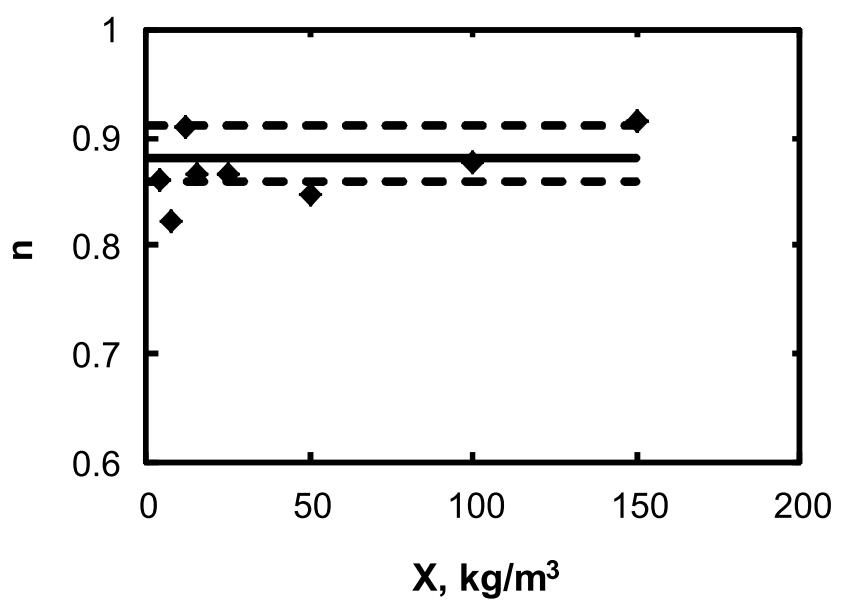

Figure 2. Dependence $n=\mathrm{f}(X)$ for the concentration yeast $X\left[\mathrm{~kg} / \mathrm{m}^{3}\right] \in<4 ; 150>$ in a suspension; $t=1 \mathrm{~h}$

The dependences of the consistency coefficient $k$ on the time $t(k=\mathrm{f}(t))$ within the range of concentration of the yeast suspension $X\left[\mathrm{~kg} / \mathrm{m}^{3}\right] \in<25 \div 250>$ are shown in Figure 3. As it is seen from these figures, the effect of the time $t$ on the $k$ values is insignificant and can be neglected. However, concentration $X$ of the yeast in a suspension affects considerably the value of the consistency index $k$. Values of the coefficient $k$ are similar for the yeast concentration $X=25 \mathrm{~kg} / \mathrm{m}^{3}$ and $X=50 \mathrm{~kg} / \mathrm{m}^{3}$ (Fig. 3) and they increase with the increasing concentration within the range $X\left[\mathrm{~kg} / \mathrm{m}^{3}\right] \in<$ $100 ; 150>$. The dependence of the consistency index $k$ on the concentration $X$ was described by means of the following equation

$k=2.76 \cdot 10^{-3} \cdot e^{9.36 \cdot 10^{-3} X}$

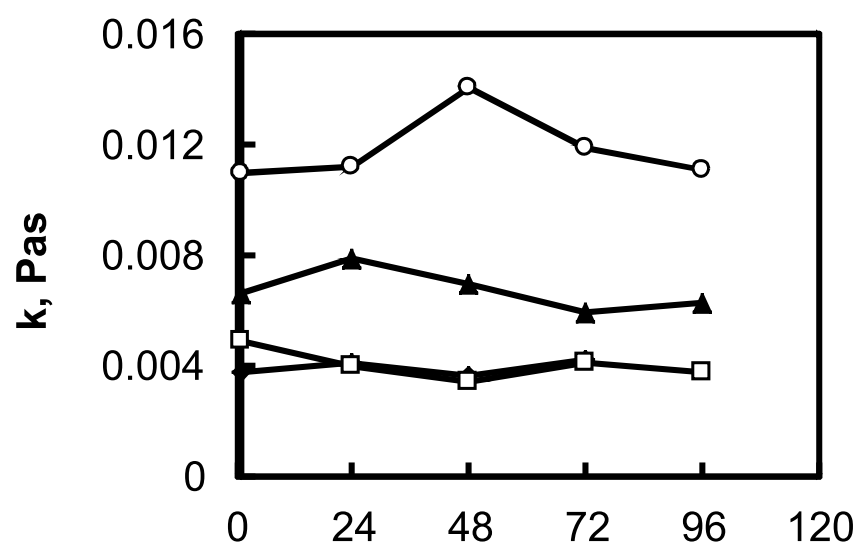

t, $h$
Equation (2) approximates the experimental results with the mean relative error $\pm 10 \%$ within the following range of the yeast concentration in the aqueous suspension $X\left[\mathrm{~kg} / \mathrm{m}^{3}\right] \in<25 \div 150>$ and time period $t[\mathrm{~h}] \in<1 \div 96>$.

In the case of the highest yeast concentration $X=$ 200 and $250 \mathrm{~kg} / \mathrm{m}^{3}$, the significant increase of the consistency coefficient $k$ was observed (Fig. 3). Values of the $k$ were contained within the ranges $0.015<k$ [Pas] $<0.019$ and $0.048<k$ [Pas] $<0.066$, respectively, for the suspension concentration $X=200 \mathrm{~kg} / \mathrm{m}^{3}$ and $X=$ $250 \mathrm{~kg} / \mathrm{m}^{3}$. It should be emphasized that flow index $n$ for both values of the concentration $X$ has the value higher than one.

Both values of the consistency index $k$, obtained experimentally and calculated from Equation (2), are compared in Figure 4. Additionally, the data for the smaller concentrations of the yeast in the suspension $X=4,8,12$ and $16 \mathrm{~kg} / \mathrm{m}^{3}$ obtained after time period $t=1 \mathrm{~h}$ are also presented in Figure 4. As the results in Figure 4 show, the $k$ values which are ascribed to

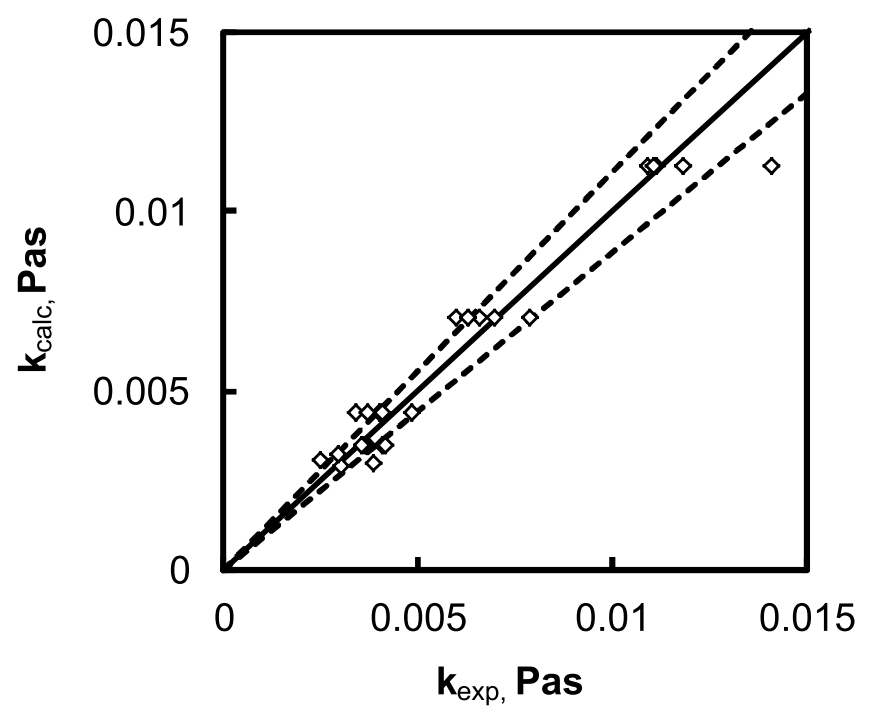

Figure 4. Comparison of the consistency index $k$, obtained from experiments $k_{\text {exp }}$ and calculated from Eq. (2) $k_{\text {calc }}$; concentration of the yeast in suspension changes within the range $X \in(4 ; 150) \mathrm{kg} / \mathrm{m}^{3}$

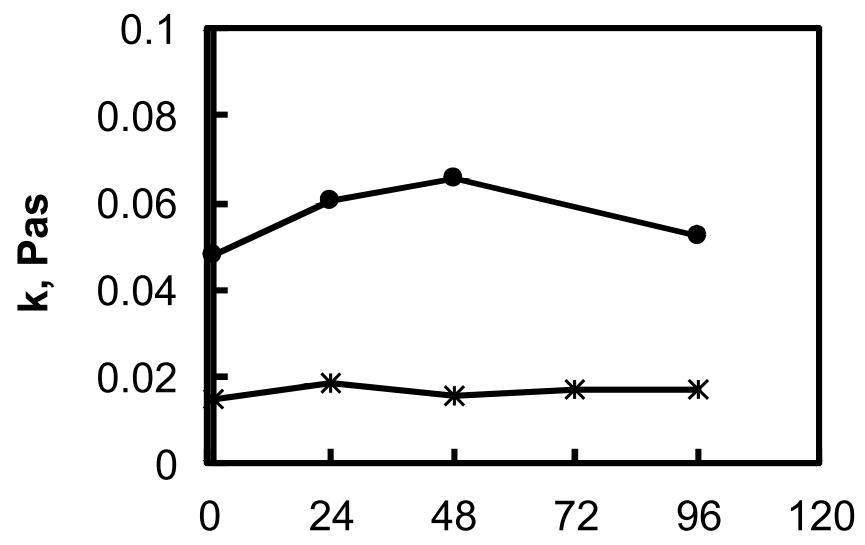

$\mathbf{t}, \mathbf{h}$

Figure 3. Dependence $k=\mathrm{f}(t)$ for the concentration $X\left[\mathrm{~kg} / \mathrm{m}^{3}\right] \in<25 ; 250>$ yeast in the suspension; $X: 25 \mathrm{~kg} / \mathrm{m}^{3}$ $(\diamond), 50 \mathrm{~kg} / \mathrm{m}^{3}(\square), 100 \mathrm{~kg} / \mathrm{m}^{3}(\Delta), 150 \mathrm{~kg} / \mathrm{m}^{3}(\bigcirc), 200 \mathrm{~kg} / \mathrm{m}^{3}(*), 250 \mathrm{~kg} / \mathrm{m}^{3}(\bullet)$ 
the smaller concentrations $X$ can be approximated with mean relative error $\pm 11 \%$ using Eq. (2).

The dependence of the apparent viscosity $\eta_{a}$ on the shear rate $\gamma$ is presented in Figure 5 for the different values of the yeast concentration $X$ in the suspension and for the period of the time $t=1 \mathrm{~h}$. As it is seen, apparent viscosity $\eta_{a}$ decreases with the increase of the yeast concentration up to $X=150 \mathrm{~kg} / \mathrm{m}^{3}$ and it increases when concentration $X$ is higher than $200 \mathrm{~kg} / \mathrm{m}^{3}$ and shear rate is higher than $3001 / \mathrm{s}$.

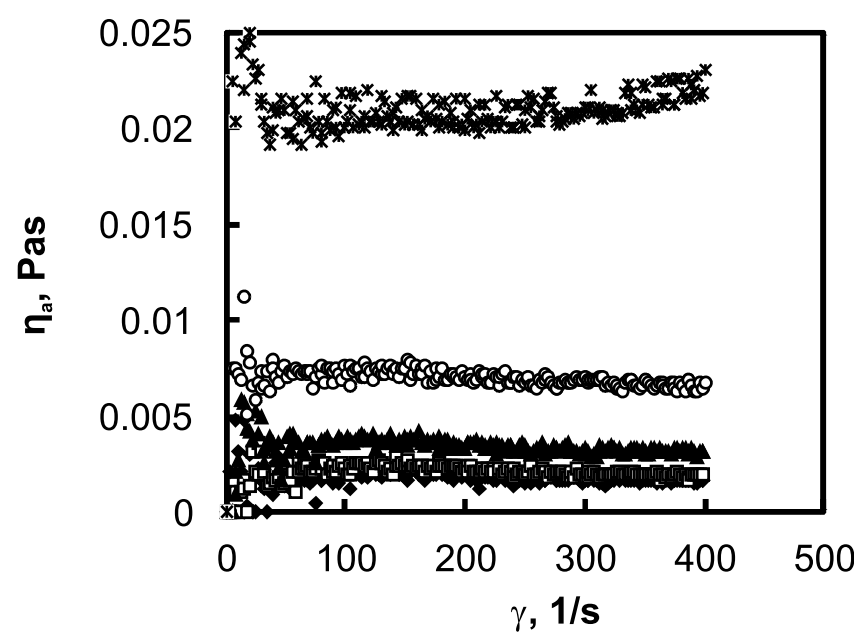

Figure 5. Viscosity curves $\eta_{\mathrm{a}}=\mathrm{f}(\gamma)$ for the concentration of yeast in the suspension changing within the range $\left.X\left[\mathrm{~kg} / \mathrm{m}^{3}\right] \in<25 ; 200\right\rangle$ and for a given time $t=1 \mathrm{~h} ; X: 25 \mathrm{~kg} / \mathrm{m}^{3}(\diamond), 50 \mathrm{~kg} / \mathrm{m}^{3}(\square)$,

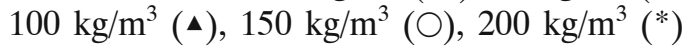

Yeasts suspended in aqueous solutions of sucrose (solution II) or honey (solution III)

On the basis of six series of the rheological measurements carried out for the yeast concentration $X=100$ $\mathrm{kg} / \mathrm{m}^{3}$ in an aqueous solution of sucrose or honey, flow curves $\tau=\mathrm{f}(\gamma)$, which relate shear stress with the shear rate, were obtained.

Figure 6a presents the dependence $\tau=f(\gamma)$ for the yeast concentration $X=100 \mathrm{~kg} / \mathrm{m}^{3}$ in the aqueous solution of sucrose with the concentration equal to $c=0.02$ or $0.1 \mathrm{~kg} / \mathrm{kg}$ and time period $t=1 \mathrm{~h}$. In Fig. $6 \mathrm{~b}$, the

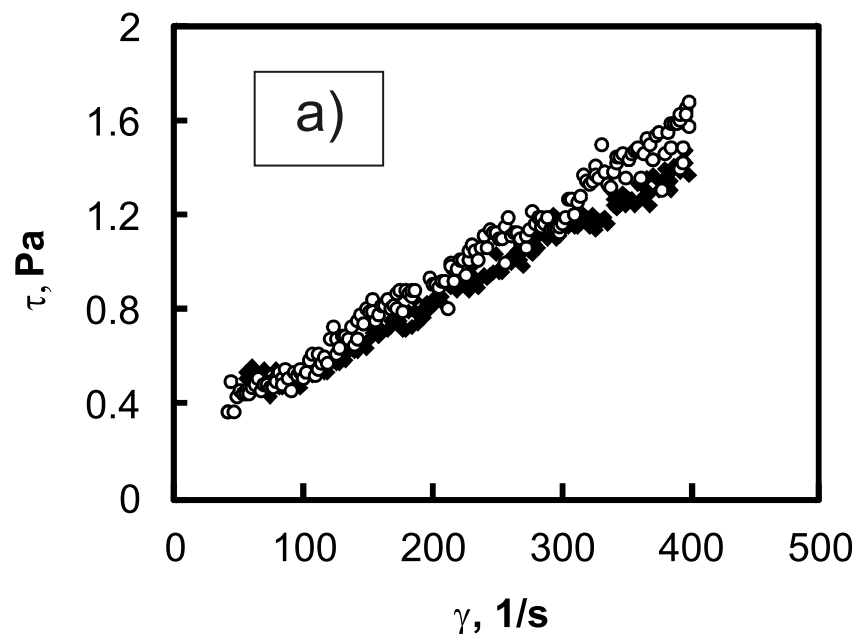

dependence $\tau=\mathrm{f}(\gamma)$ is shown for the yeast concentration $X=100 \mathrm{~kg} / \mathrm{m}^{3}$ in the aqueous solution of honey with the concentration $(c=0.02$ or $0.1 \mathrm{~kg} / \mathrm{kg}$ and time period $t=1 \mathrm{~h}$ ). Small effect of the sucrose and honey concentration is observed only for both values of the $c$ within the range of the shear rate $501 / \mathrm{s}<\gamma<120$ $1 / \mathrm{s}$. For assumed constant value of the $\gamma$, differences in the values of the shear stress $\tau$ appear for both $c$ concentrations with the increase of the shear rate $\gamma>120$ $1 / \mathrm{s}$. Higher values of the shear stress $\tau$ are characteristic for the sucrose and honey concentration equal to $10 \%$.

In Figure 7, flow curves $\tau=\mathrm{f}(\gamma)$ are shown for the time $t=48 \mathrm{~h}$ and yeast concentration $X=100 \mathrm{~kg} / \mathrm{m}^{3}$ in the aqueous solution with the concentration of sucrose equal to $c=0.02$ or $0.2 \mathrm{~kg} / \mathrm{kg}$. In this case, effect of the sucrose concentration $c$ on the shear stress $\tau$ also reveals for the values of the shear rate higher than $\gamma>1201 / \mathrm{s}$.

Effect of the time $t$ (calculated as a period after time of the sample preparation) on the rheological properties of the yeast suspension with concentration $X=$ $100 \mathrm{~kg} / \mathrm{m}^{3}$ in the aqueous solution of sucrose with the

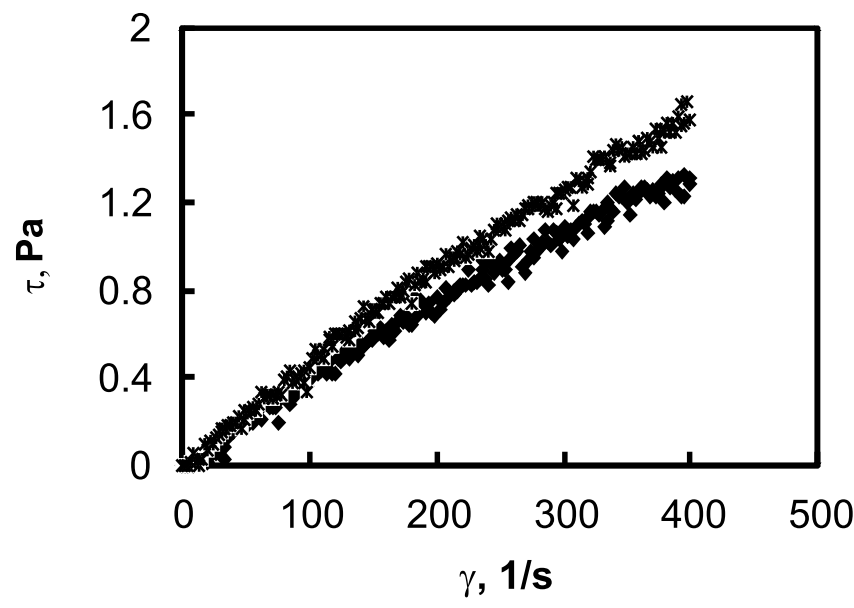

Figure 7. Flow curves $\tau=\mathrm{f}(\gamma)$ for the yeast concentration $X=100 \mathrm{~kg} / \mathrm{m}^{3}$ in the aqueous solution of sucrose with the concentration $c=0.02$ or $c=$ $0.2 \mathrm{~kg} / \mathrm{kg}$ and for the time $t=48 \mathrm{~h}$ (calculated after time of the sample preparation); $c: 0.02$ $(\diamond), 0.2(*)$

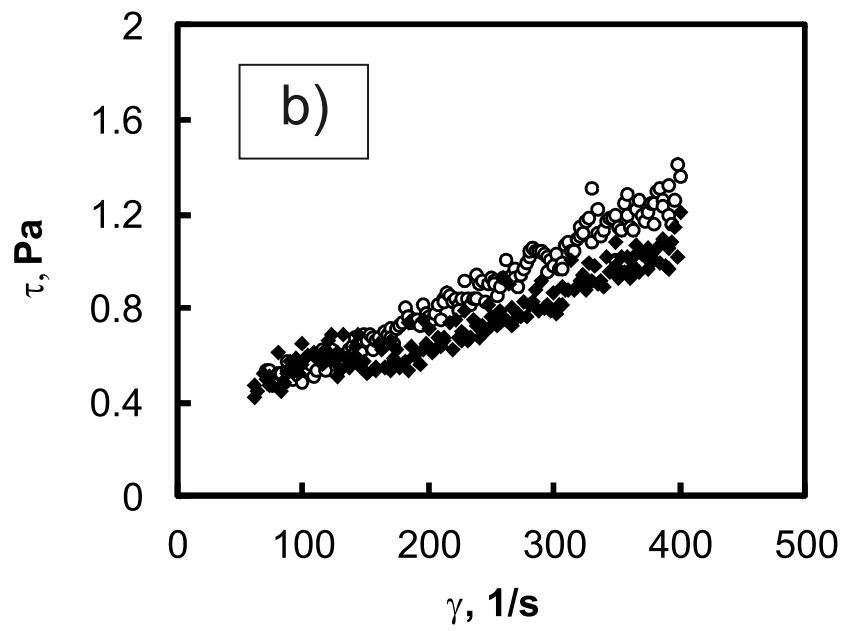

Figure 6. Flow curves $\tau=\mathrm{f}(\gamma)$ for the yeast concentration $X=100 \mathrm{~kg} / \mathrm{m}^{3}$; a) in the aqueous solution of sucrose with the concentration $c=0.02$ or $c=0.1 \mathrm{~kg} / \mathrm{kg}$ and for the time $t=1 \mathrm{~h} ; c: 0.02(\diamond), 0.1(\bigcirc)$; b) in the aqueous solution of honey with the concentration $c=0.02$ or $c=0.1 \mathrm{~kg} / \mathrm{kg}$ and for the time $t=1 \mathrm{~h} ; c: 0.02(\diamond)$, $0.1(\bigcirc)$ 

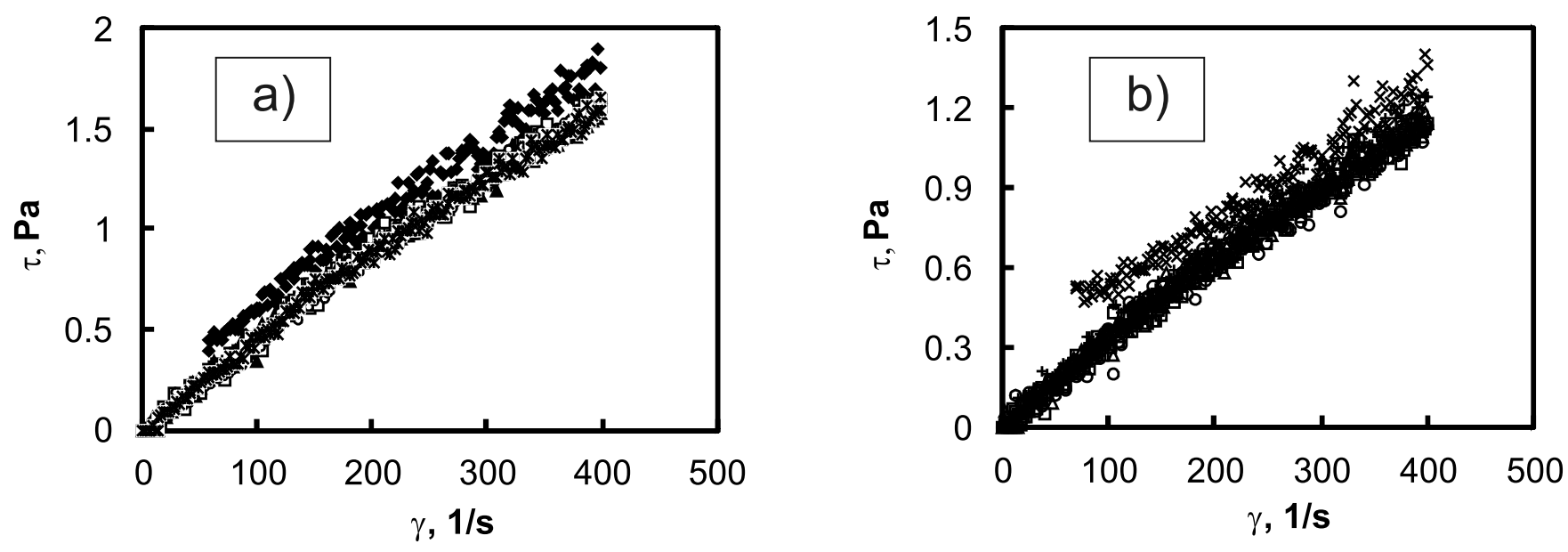

Figure 8. Flow curves $\tau=\mathrm{f}(\gamma)$ for the yeast concentration $X=100 \mathrm{~kg} / \mathrm{m}^{3}$; a) in the aqueous solution of sucrose with the concentration $c=0.2 \mathrm{~kg} / \mathrm{kg}$ and for the time $t=1,24,48,72,144 \mathrm{~h}$ (calculated after time of the sample preparation); $t: 1 \mathrm{~h}(\diamond), 24 \mathrm{~h}(\square), 48 \mathrm{~h}(\mathbf{\Delta}), 72 \mathrm{~h}(\bigcirc), 144 \mathrm{~h}(*) ; \mathrm{b})$ in the aqueous solution of honey with the concentration $c=0.1 \mathrm{~kg} / \mathrm{kg}$ and for the time $t=1,24,48,72,96 \mathrm{~h}$ (calculated after time of the sample preparation); $t: 1 \mathrm{~h}(\mathrm{x}), 24 \mathrm{~h}(+), 48 \mathrm{~h}(\Delta), 72 \mathrm{~h}(\bigcirc), 96 \mathrm{~h}(\square)$

concentration $c=0.2 \mathrm{~kg} / \mathrm{kg}$ is compared in Figure $8 \mathrm{a}$ for different periods of time equal to $t=1 \mathrm{~h}, 24 \mathrm{~h}$, $48 \mathrm{~h}, 72 \mathrm{~h}$ and $144 \mathrm{~h}$. The data presented in Figure 8a show that rheological properties of such yeast suspension change significantly during first 24 hours only, while these changes are not important after time periods $t=$ 24, 48, 72 and $144 \mathrm{~h}$.

The same tendency is observed (Fig. $8 \mathrm{~b}$ ) in case of the yeast with concentration $X=100 \mathrm{~kg} / \mathrm{m}^{3}$ suspended in the aqueous solution of honey with the concentration $c=0.1 \mathrm{~kg} / \mathrm{kg}$. The rheological properties of such yeast suspension change significantly during first 24 hours only, too, compared to those characteristics obtained after longer sampling times. Therefore, differences in the course of the flow curves determined for time periods $t=24,48,72$ and $96 \mathrm{~h}$ can be neglected.

Set of data, including the results obtained for the yeasts with the concentration $X=100 \mathrm{~kg} / \mathrm{m}^{3}$ suspended in both aqueous solutions of sucrose with the concentration $c=0.02,0.05,0.1$ or $0.2 \mathrm{~kg} / \mathrm{kg}$ and of honey with the concentration $c=0.02$ or $0.1 \mathrm{~kg} / \mathrm{kg}$, as well as for the time periods $t=1,24,48,72,96$ and $144 \mathrm{~h}$, was quantitatively described using following equation

$\tau=\left(A \cdot c^{B}\right) \cdot \gamma^{(E \ln c+D)}$

where shear rate $\gamma \leq 4001 / \mathrm{s}, c$ denotes mass fraction of the sucrose or honey in aqueous solution, $\mathrm{kg}_{\text {sucrose }} /$ $\mathrm{kg}_{\text {solution }}$ or $\mathrm{kg}_{\text {honey }} / \mathrm{kg}_{\text {solution }}$, and $A, B, \mathrm{E}, D$ are constant values determined for the time $t=1,24,48,72$ and 144 $\mathrm{h}$ (solution II) or $t=1,24,48,72$ and $96 \mathrm{~h}$ (solution
III). These values of the constant in Equation (3) for the yeasts with the concentration $X=100 \mathrm{~kg} / \mathrm{m}^{3}$ suspended in aqueous solution of sucrose with the concentration $c$ $=0.02,0.05,0.1,0.2 \mathrm{~kg} / \mathrm{kg}$ and the time periods $t=1 \mathrm{~h}$ and $t=24,48,72,96$ and $144 \mathrm{~h}$ are collected in Table 1 .

Equation (3) also describes experimental data obtained for the yeasts with the concentration $X=100$ $\mathrm{kg} / \mathrm{m}^{3}$ suspended in aqueous solution of honey with the concentration $c=0.02, \mathrm{c}=0.1 \mathrm{~kg} / \mathrm{kg}$ and the time periods $t=1 \mathrm{~h}$ and $t=24,48,72$ and $96 \mathrm{~h}$ (solution III). Constant values of Equation 3 obtained for the yeasts with the concentration $X=100 \mathrm{~kg} / \mathrm{m}^{3}$ suspended in aqueous solution of honey with the concentration $c=$ $0.02, \mathrm{c}=0.1 \mathrm{~kg} / \mathrm{kg}$ and, separately, for the time periods $t=1 \mathrm{~h}$ and $t=24,48,72$ and $96 \mathrm{~h}$ (solution III) are presented in Table 2.

Figure 9a illustrates differences between values of the apparent viscosity $\eta_{a}$, obtained for the aqueous solution of the yeast ( $X=100 \mathrm{~kg} / \mathrm{m}^{3}, c=0$, solution I) and for the aqueous solution with sucrose concentration $c=0.05$ and $0.2 \mathrm{~kg} / \mathrm{kg}$ and yeast concentration $X=100 \mathrm{~kg} / \mathrm{m}^{3}$ (solution II) for which this viscosity was determined after time $t=1 \mathrm{~h}$. As it is seen solution II has higher apparent viscosity $\eta_{a}$ than solution I. However, these differences in apparent viscosity decrease after time $t(t=48 \mathrm{~h})$ as it results from Figure 9b. Sucrose in aqueous solution is nutrient medium for the yeast cells and it may be gradually exhausted. After further time $t$ values of the apparent viscosity $\eta_{a}$ for both solutions

Table 1. Values of the constants in Equation (3) for the yeasts suspended in aqueous solution of sucrose (solution II)

\begin{tabular}{|l|c|c|c|c|c|}
\hline \multicolumn{1}{|c|}{ Solution } & $\mathrm{A}$ & $\mathrm{B}$ & $\mathrm{E}$ & $\mathrm{D}$ & $\pm \Delta$ \\
\hline $\begin{array}{l}X=100 \mathrm{~kg} / \mathrm{m}^{3} ; t=1 \mathrm{~h} \\
c=0.02,0.05,0.1,0.2 \mathrm{~kg} / \mathrm{kg}\end{array}$ & $1.85 \cdot 10^{-2}$ & $-5.88 \cdot 10^{-3}$ & $1.71 \cdot 10^{-2}$ & 0.785 & $6 \%$ \\
\hline $\begin{array}{l}X=100 \mathrm{~kg} / \mathrm{m}^{3} ; t=24,48,72,144 \mathrm{~h} \\
c=0.02,0.05,0.1,0.2 \mathrm{~kg} / \mathrm{kg}\end{array}$ & $6.6 \cdot 10^{-3}$ & $-4.6 \cdot 10^{-2}$ & $1.99 \cdot 10^{-2}$ & 0.936 & $10 \%$ \\
\hline
\end{tabular}

Table 2. Values of the constants in Equation (3) for the yeasts suspended in aqueous solution of honey (solution III)

\begin{tabular}{|l|c|c|c|c|c|}
\hline \multicolumn{1}{|c|}{ Solution } & $\mathrm{A}$ & $\mathrm{B}$ & $\mathrm{E}$ & $\mathrm{D}$ & $\pm \Delta$ \\
\hline $\begin{array}{l}X=100 \mathrm{~kg} / \mathrm{m}^{3} ; t=1 \mathrm{~h} \\
c=0.02,0.1 \mathrm{~kg} / \mathrm{kg}\end{array}$ & $1.34 \cdot 10^{-2}$ & -0.258 & $5.94 \cdot 10^{-2}$ & 0.792 & $8 \%$ \\
\hline $\begin{array}{l}X=100 \mathrm{~kg} / \mathrm{m}^{3} ; t=24,48,72,96 \mathrm{~h} \\
c=0.02,0.1 \mathrm{~kg} / \mathrm{kg}\end{array}$ & $7.1 \cdot 10^{-3}$ & $7.8 \cdot 10^{-2}$ & $1.3 \cdot 10^{-3}$ & 0.886 & $13 \%$ \\
\hline
\end{tabular}



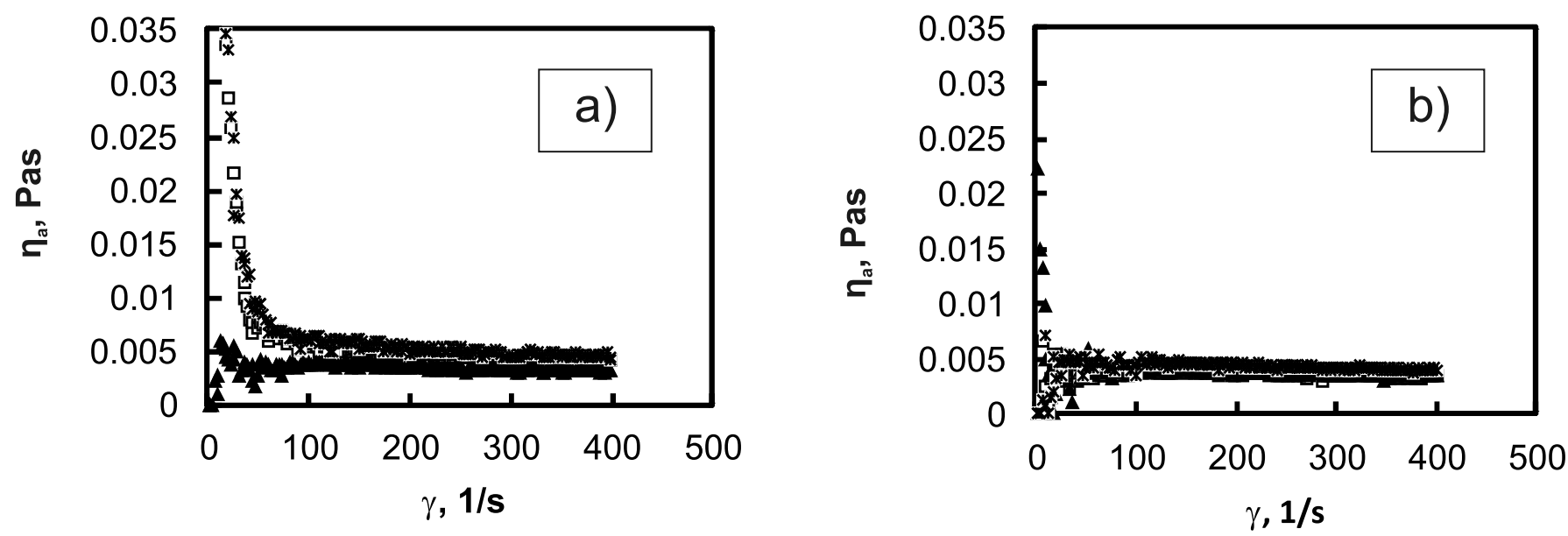

Figure 9. Dependence $\eta_{\mathrm{a}}=\mathrm{f}(\gamma)$ for yeast suspension $\left(X=100 \mathrm{~kg} / \mathrm{m}^{3}\right)$; a) in aqueous solution with sucrose concentration $c=0, c=0.05, c=0.2 \mathrm{~kg} / \mathrm{kg}$ for the time $t=1 \mathrm{~h} ; c: 0(\mathbf{\Delta}), 0.05(\square), 0.2(*) ; \mathrm{b})$ in aqueous solution with sucrose concentration $c=0, c=0.05, c=0.2 \mathrm{~kg} / \mathrm{kg}$ for the time $t=48 \mathrm{~h} ; c: 0(\mathbf{\Delta}), 0.05(\square), 0.2(*)$

I and II become comparable. These results show that rheological properties of the aqueous solution of yeast $\left(X=100 \mathrm{~kg} / \mathrm{m}^{3}\right)$ with sucrose concentration $c=0.02$, $0.05,0.1,0.2 \mathrm{~kg} / \mathrm{kg}$ change with the time in the first day from the sample preparation. However, these changes disappear after successive days during which the samples are tested.

Viscosity curves $\eta_{a}=\mathrm{f}(\gamma)$ presenting the dependence of the apparent viscosity $\eta_{a}$ as a function of shear rate $\gamma$ for time $t=1 \mathrm{~h}$ and three tested suspensions of yeast with the concentration $X=100 \mathrm{~kg} / \mathrm{m}^{3}$ dissolved in demineralised water or in aqueous solutions of sucrose or honey with the concentration $c=0.1 \mathrm{~kg} / \mathrm{kg}$ (solutions I, II and III) are compared in Figure 10. Taking into account that dynamic viscosity for the solvent, water, in temperature $23^{\circ} \mathrm{C}$ is equal to $0.9358 \times 10^{-3}$ Pas (Perry's Handbook $\left.{ }^{11}\right)$, apparent viscosity $\eta_{a}$ is about three times higher for the suspension of yeast in demineralised water (solution I). Moreover, the presence of the nutrient in the yeasts suspension (solutions II and III) affects noticeably the increase of the apparent viscosity $\eta_{a}$. This effect is especially significant within the range of the shear rate $\gamma<1001 / \mathrm{s}$, while the values of the apparent viscosity

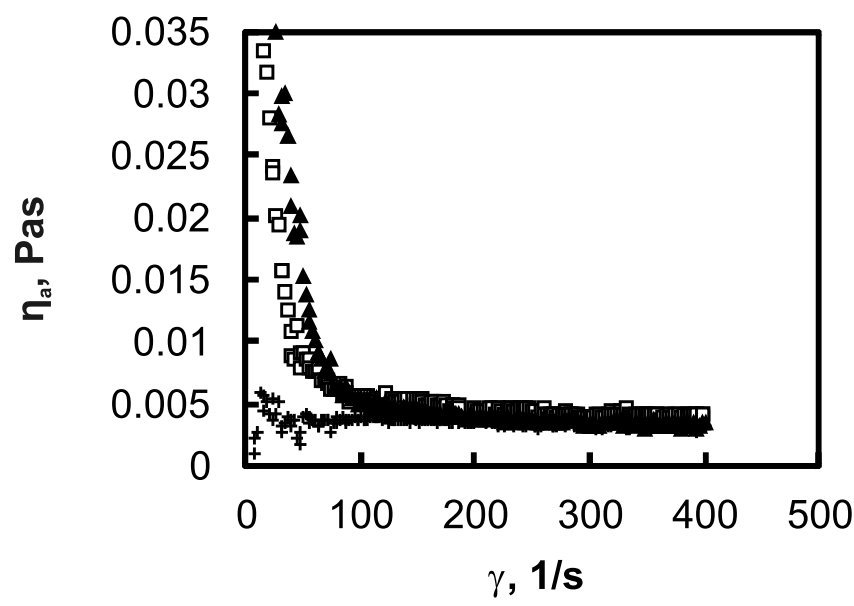

Figure 10. Dependence $\eta_{\mathrm{a}}=\mathrm{f}(\gamma)$ for yeast $(X=100 \mathrm{~kg} /$ $\left.\mathrm{m}^{3}\right)$ suspended in: demineralised water, $c=$ $0(+)$; aqueous solution of sucrose with the concentration $c=0.1 \mathrm{~kg} / \mathrm{kg}(\square)$; aqueous solution of honey with the concentration $c=$ $0.1 \mathrm{~kg} / \mathrm{kg}(\mathbf{\Delta})$; time $t=1 \mathrm{~h}$ $\eta_{a}$ are higher for the honey used as nutrient compared to sucrose.

Values of the shear stress and apparent viscosity may depend on the type of the nutrient used in the study and their consumption by yeasts in a process time. The sucrose content $x$ in aqueous solution of the sucrose or honey was measured using Refractometer HI96801. Relative sucrose content $x / x_{1 h}$ (where $x_{1 h}$ denotes sucrose content in aqueous solution after 1 hour) is shown in Figure 11 as a function of the process time. In Figure 11 , the data for sucrose in aqueous solution of the sucrose or honey with the concentration $c=0.02$ or 0.1 $\mathrm{kg} / \mathrm{kg}$ are compared for yeasts with the concentration of
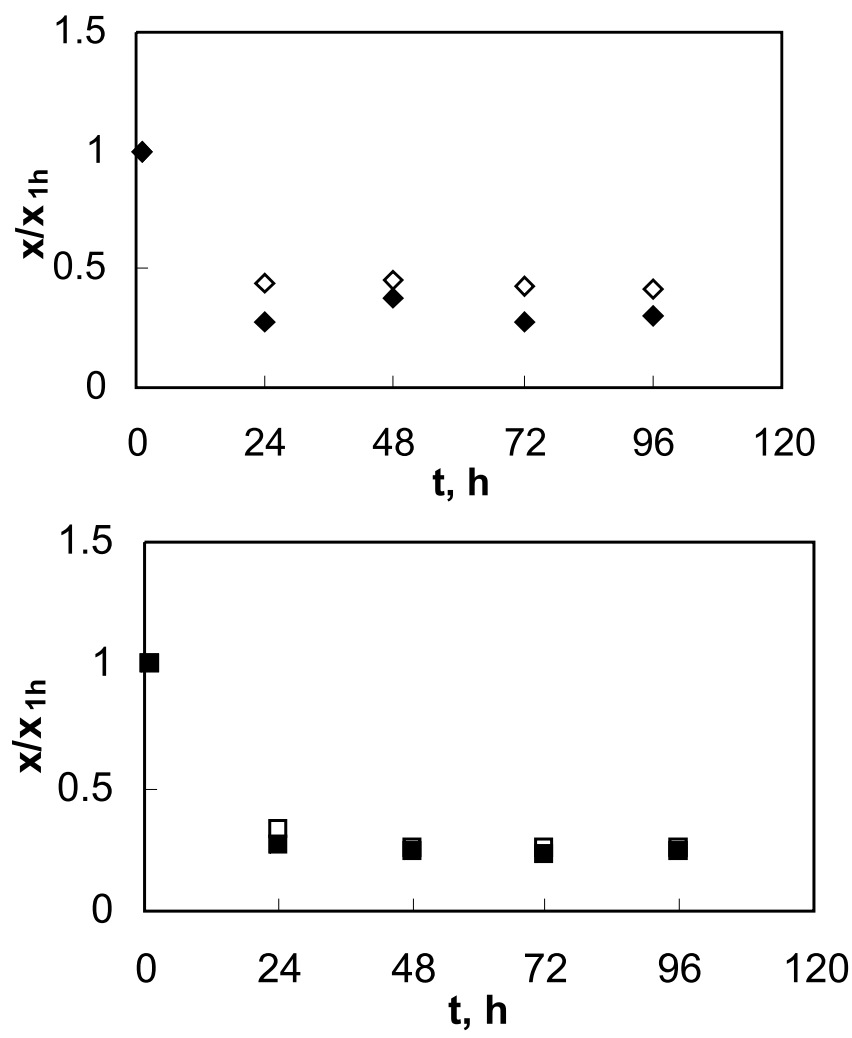

Figure 11. Dependence $x / x_{1 h}=\mathrm{f}(t)$ for yeast $(X=25 \mathrm{~kg}$ / $\left.\mathrm{m}^{3}\right)$ suspended in: aqueous solution of sucrose with the concentration $c=0.02 \mathrm{~kg} / \mathrm{kg}(\diamond)$ and $c=0.1 \mathrm{~kg} / \mathrm{kg}(\boldsymbol{\square})$; aqueous solution of honey with the concentration $c=0.02 \mathrm{~kg} / \mathrm{kg}(\diamond)$ and $c=0.1 \mathrm{~kg} / \mathrm{kg}(\square)$ 
$X=25 \mathrm{~kg} / \mathrm{m}^{3}$. For example, comparison of the values of sucrose content for both process times equal to $t$ $=1 \mathrm{~h}$ and $t=24 \mathrm{~h}$, respectively, shows that sucrose content in the nutrient decreases about $70 \%$ for the aqueous solution of sucrose of concentration $c=0.02$ $\mathrm{kg} / \mathrm{kg}$, as well as about of $60 \%$ for the aqueous solution of honey of concentration $c=0.02 \mathrm{~kg} / \mathrm{kg}$ (Fig. 11). As Figure 11 shows, sucrose content in nutrient decreases slightly only after $t=24 \mathrm{~h}$.

In Figure 12, our experimentally obtained results concerning consistency index $k$ (two point dashed line) and flow index $n$ (one point dashed line) as a function of the biomass concentration $X$ are compared with the literature data (Mancini \& Moresi ${ }^{\mathbf{9}}$, dashed line). Both our experimental and literature values of the consistency index $k$ agree within the range of low $X$ values. The highest differences between experimental and literature values of the $k$ equal to about $30 \%$ are observed for the high biomass concentration $X$, ie. $X=100$ or $150 \mathrm{~kg} / \mathrm{m}^{3}$. Comparison of the experimental and literature value of

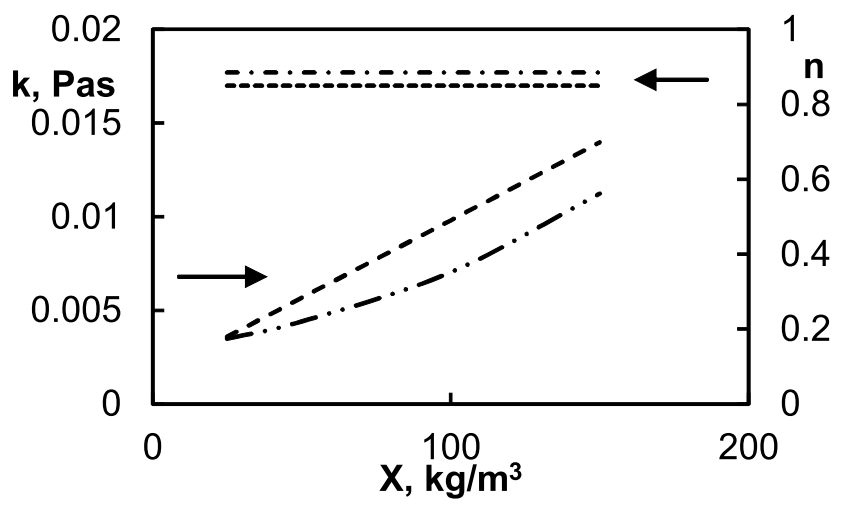

Figure 12. Comparison of dependences $k=f(\mathrm{X})$ and $n$ $=f(\mathrm{X})$ for the concentration yeast $X\left[\mathrm{~kg} / \mathrm{m}^{3}\right]$ $\in<25 ; 150\rangle$ in a suspension; dashed lines Mancini \& Moresi ${ }^{9}$, one or two point dashed lines - experimental data

the flow index $n$ show that experimental value of $n=$ $0.885 \pm 0.026$ is consistent with the result $n=0.85 \pm 0.03$ obtained by Mancini \& Moresi ${ }^{9}$.

In Figure 13, our experimental data and literature results are compared in the form of the relative visco-

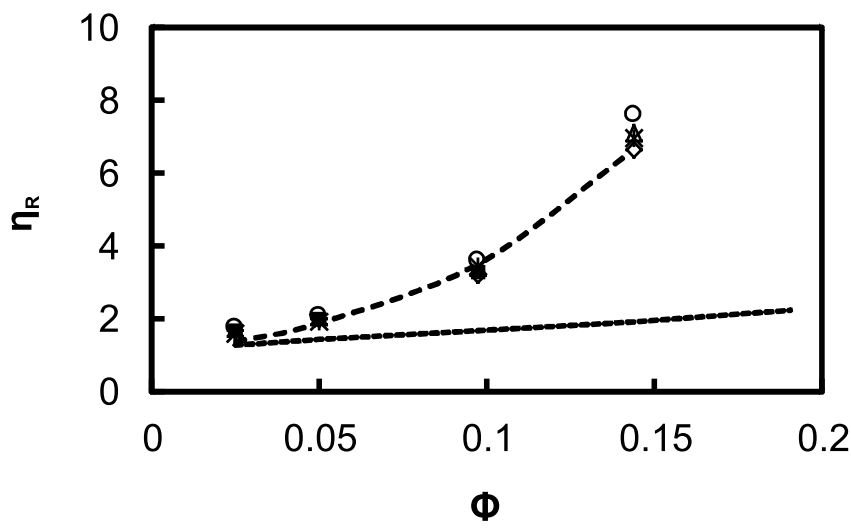

Figure 13. Comparison of relative viscosity $\eta_{\mathrm{R}}=\mathrm{f}(\Phi)$ for experimental and literature data; $t: 1 \mathrm{~h}(\searrow), 24$ h $(\Delta), 48$ h (O), 72 h ( $(\Delta), 96$ h (*); dashed line - Mancini \& Moresi ${ }^{9}$, point dashed line - Reuss et al. ${ }^{6}$ sity $\eta_{\mathrm{r}}=\eta / \eta_{\mathrm{w}}$ (where $\eta_{\mathrm{w}}$ denotes the viscosity of the continous medium) as a function of the yeast volumetric fraction $\Phi$. Experimental values (points, temeperature $23^{\circ} \mathrm{C}$ ) agree with the data (temperature $5^{\circ} \mathrm{C}$ ) obtained by Manicini \& Moresi ${ }^{9}$. Experimental values are also consistent with the Reuss et $\mathrm{al}^{\mathbf{6}}$. results (temperature $30^{\circ} \mathrm{C}$ ) within the range of the low values of the $\Phi$. Different measurement temperatures affecting process conditions can be responsible for discrepancy of the experimental and literature values (Reuss et al. ${ }^{6}$ ) within the range of high $\Phi$ values.

\section{CONCLUSIONS}

On the basis of the experimental study, concerning the effects of the nutrient type and its concentration on rheological behaviour of the suspension of baker's yeast with different concentration, it can be stated that within the range of the performed measurements

For the aqueous suspension of the yeast with concentration $X \in(25 ; 150) \mathrm{kg} / \mathrm{m}^{3}$, statistically evaluated value of the flow index $n$ is less than one and it is equal to $n=0.885 \pm 0.026$. Within this range of the yeast concentration and for the time period $t \in(1 ; 96) \mathrm{h}$, values of the consistency index $k$ describes Equation (2). Therefore, this suspension behaves as the shear thinning fluid within the tested ranges of the concentration and time.

Value of the flow index $n$ is higher than one for the aqueous suspension of the yeast with concentration $X=$ $250 \mathrm{~kg} / \mathrm{m}^{3}$, therefore this biological suspension behaves as shear thickening fluid within the range of the carried out experiments.

For the yeast suspension of concentration $X=100$ $\mathrm{kg} / \mathrm{m}^{3}$ and sucrose concentration $c=0.02,0.05,0.1$ and $0.2 \mathrm{~kg} / \mathrm{kg}$ or honey concentration $c=0.02$ and $0.1 \mathrm{~kg} /$ $\mathrm{kg}$, the changes of the rheological properties with time were observed only during first day from the sample preparation. The greatest content of sucrose in the time period can be responsible for this rheological behaviour of the fluid.

Flow curves were described by means of the Equation (3) which is applicable to the time $t=1 \mathrm{~h}$ for solutions II and III, as well as within the time periods $t \in<24 \mathrm{~h} ; 144 \mathrm{~h}>$ (solutions II) or $t \in<24 \mathrm{~h} ; 96 \mathrm{~h}>$ (solutions III).

\section{Symbols}

c sucrose or honey concentration, $\mathrm{kg}$ nutrient $/ \mathrm{kg}$ solution

$k \quad$ consistency index, Pas

$n$ flow index

$t$ time, h

$X$ yeast concentration, $\mathrm{kg} \mathrm{m}^{-3}$

$x \quad$ sucrose content in solution, \% Brix

\section{Greek Letters}

$\eta_{a}$ apparent viscosity, Pas

$\eta_{R}$ relative viscosity,

$\gamma$ shear rate, $\mathrm{s}^{-1}$

$\tau \quad$ shear stress, $\mathrm{Pa}$ 


\section{LITERATURE CITED}

1. Sato, A.C.K., Perrechil, F.A. \& Cunha, R.L. (2013). Rheological behaviour of suspensions dispersed in non-Newtonian matrix. Appl. Rheol. 23, 4, 45397 (10 pages). DOI: 10.3933/ ApplRheol-23-45397.

2. Pereira de Oliveira, L.A., Castro Gomes, J.P. \& Nepomuceno, M.C.S. (2013). The influence of wastes materials on the rheology of rendering mortars. Appl. Rheol. 23, 1, 15505 (11 pages). DOI: 10.3933/ApplRheol-23-15505.

3. Klein, J., Maia, J., Vicente, A. A., Domingues, L., Teixeira, A.J. \& Jurascik, M. (2005). Relationships Between Hydrodynamics and Rheology of Flocculating Yeast Suspensions in a High-Cell-Density Airlift Bioreactor. Biotech. Bioeng. 89, 393-399. DOI: 10.1002/bit.20335.

4. Yu, L., Wang, H., Wang, L. \& Bai, F.W. (2010). Rheological property of self-flocculating yeast suspension. Biochem. Eng. J. 52, 50-54. DOI: 10.1016/j.bej.2010.07.003.

5. Charles, M. (1978). Technical aspects of the rheological properties of microbial cultures. Adv. Biochem. Eng./ Biotech. 8, 1-62. DOI:10.1007/3-540-08557-2 1.

6. Reuss, M., Josić, D., Popović, M. \& Bronn, W.K. (1979). Viscosity of Yeast Suspensions. Eur. J. Appl. Microbiol. Biotechnol. 8, 167-175. DOI: 10.1007/BF00506180.

7. EI-Temtamy, S., Farahat, L., Nour el-din, A. \& Gaber A. (1982). Non-Newtonian Behaviour of Yeast Suspensions. Eur. J. Appl. Microbiol. Biotechnol. 15, 156-160. DOI: 10.1007/BF00511240.

8. Speers, R.A., Durance, T.D., Tung, M.A. \& Tou, J. (1993). Colloidal Properties of Flocculent and Nonflocculent Brewing Yeast Suspensions. Biotechnol. Prog. 9, 267-272. DOI: $10.1021 / \mathrm{bp00021a005.}$

9. Mancini, M. \& Moresi, M. (2000). Rheological behaviour of baker's yeast suspensions. J. Food Eng. 44, 225-231. DOI: 10.1016/S0260-8774(00)00030-3.

10. Ferguson, J. \& Kembłowski, Z. (1991). Appl. Fluid Rheol3. Cambridge, Elsevier Science Publishers Ltd.

11. Perry's Chemical Engineer' Handbook. (1984). McGraw - Hill. 